\title{
Translating scientific evidence into the art of caring for critically ill children across the globe
}

From the time that the earliest pediatric intensive care units (ICUs) were established in Europe, Australia, and North America in the 1950s and 60s, the specialty of pediatric critical care medicine has grown globally by leaps and bounds (1). Pediatric critical care medicine emerged as a unique specialty from the intersection of five important fields in medicine: adult respiratory intensive care, neonatology, and neonatal intensive care, pediatric general surgery, pediatric cardiac surgery, and pediatric anesthesiology. Following the establishment of pediatric ICUs, pediatric critical care medicine grew rapidly as an academic subspecialty to develop strong standards of care and train future generations of clinicians and scientists. Globally, pediatric critical care medicine has spread across all continents with numerous leaders and distinguished clinicians in many countries leading to further growth in clinical care and scientific research to fuel discovery and innovation (1-3). Multiple international societies such as the World Federation of Pediatric Intensive and Critical Care Societies (WFPICCS), Society of Critical Care Medicine (SCCM), European Society of Pediatric and Neonatal Intensive Care (ESPNIC), Australian and New Zealand Intensive Care Society (ANZICS), Sociedad Latinoamericana de Cuidados Intensivos Pediátricos (SLACIP), Red Colaborativa Pediatrcia de Lationamerica (LARed) and Pediatric Acute \& Critical Care Medicine Asian Network (PACCMAN) have broadened the reach of pediatric critical care medicine across every country with cutting edge research collaboration and excellence in clinical care delivery models. It can be rightly said that pediatric critical care medicine belongs to the global village of practitioners and scientists who strive tirelessly to improve the health and future of critically ill children across the world.

Advances in pediatric critical care medicine encompass a better understanding of disease states, newer interventions with innovations in therapeutics and devices, and better team integration of multiple disciplines and workflow processes to enhance the quality of care and outcomes from critical illness in children. From the early days of physician-driven care of infants with acute respiratory failure requiring manual hand ventilation to the modern interdisciplinary ICU with complex decision support and advanced ventilator technologies involving smart devices and skilled teams of physicians, nurses, respiratory therapists, and pharmacists, the clinical care of critically ill children has been greatly enhanced through advances in scientific research and quality improvement methods. This special series on pediatric critical care medicine is a curated collection of cutting-edge articles by leading clinician-scientists from across the world in the field of pediatric critical care medicine. As editors, we are particularly proud to have assembled this series of articles authored by a diverse group of multidisciplinary experts from different geographical regions. These articles emphasize how scientific evidence can build the foundation for outstanding clinical care to improve outcomes in pediatric critical illness. Some articles cover well-known disease states such as acute respiratory distress syndrome (4,5), severe sepsis $(6,7)$ and septic shock (8), and traumatic brain injury (9) and provide the latest translational science context that serves to underpin our current understanding of how best to care for these children (10-12). Other articles emphasize the evidence for best practices for ICU interventions such as sedation management (13), nutrition therapy $(14,15)$, and early mobilization with rehabilitation (16). These articles also focus on topical and relevant issues such as pandemic considerations for the ICU (17), the role of the microbiota (14), and moral and ethical dilemmas in the care of critically ill children (18-21). Together, these articles serve as a compendium of how best to translate scientific evidence into the art of caring for critically ill children across the globe.

\section{Acknowledgments}

Funding: None.

\section{Footnote}

Provenance and Peer Review: This article was commissioned by the editorial office, Translational Pediatrics for the series "Pediatric Critical Care". The article did not undergo external peer review. 
Conflicts of Interest: All authors have completed the ICMJE uniform disclosure form (available at https://dx.doi.org/10.21037/ tp-21-429). The series "Pediatric Critical Care" was commissioned by the editorial office without any funding or sponsorship. Jan Hau Lee served as the unpaid Guest Editor of the series and serves as an unpaid editorial board member of Translational Pediatrics from Nov 2019 to Nov 2021. Debbie Long served as the unpaid Guest Editor of the series. Vijay Srinivasan served as the unpaid Guest Editor of the series and serves as an unpaid editorial board member of Translational Pediatrics from Oct 2019 to Sep 2021. JHL is the Chairperson of Pediatric Acute \& Critical Care Medicine Asian Network (PACCMAN). DL is a Member of Officer Bearer Group, Australian and New Zealand Intensive Care Society (ANZICS), Paediatric Study Group and Chairperson of Long Term Outcomes Working Group. VS is an Executive Committee Member, American Academy of Pediatrics Section of Critical Care (AAP SOCC); Executive Committee Member, Society of Critical Care Medicine (SCCM) Pediatric Section; Vice-Chair, Nutrinet Pediatric Acute Lung Injury and Sepsis Investigators (PALISI) Network. He also serves as Chair, DSMB for the SUPRESS-CHD clinical trial.

Ethical Statement: The authors are accountable for all aspects of the work in ensuring that questions related to the accuracy or integrity of any part of the work are appropriately investigated and resolved.

Open Access Statement: This is an Open Access article distributed in accordance with the Creative Commons AttributionNonCommercial-NoDerivs 4.0 International License (CC BY-NC-ND 4.0), which permits the non-commercial replication and distribution of the article with the strict proviso that no changes or edits are made and the original work is properly cited (including links to both the formal publication through the relevant DOI and the license). See: https://creativecommons.org/ licenses/by-nc-nd/4.0/.

\section{References}

1. Levin DL, Downes JJ, Todres ID. History of pediatric critical care medicine. J Pediatr Intensive Care 2013;2:147-67.

2. Epstein D, Brill JE. A history of pediatric critical care medicine. Pediatr Res 2005;58:987-96.

3. Qian S, Xu F. History of pediatric critical care medicine in the mainland of China. Pediatr Investig 2019;3:69-71.

4. Yehya N. Potential therapeutics in pediatric acute respiratory distress syndrome: what does the immune system have to offer? A narrative review. Transl Pediatr 2021. doi: 10.21037/tp-20-341

5. Miller AG, Bartle RM, Feldman A, et al. A narrative review of advanced ventilator modes in the pediatric intensive care unit. Transl Pediatr 2020. doi: 10.21037/tp-20-332

6. Ranjit S, Kissoon N. Challenges and Solutions in translating sepsis guidelines into practice in resource-limited settings. Transl Pediatr 2021. doi: 10.21037/ tp-20-310

7. Wiens MO, Kissoon N, Holsti L. Challenges in pediatric post-sepsis care in resource limited settings: a narrative review. Transl Pediatr 2021. doi: 10.21037/ tp-20-390

8. Schlapbach LJ, de Oliveira CF, Raman S, et al. Metabolic resuscitation in pediatric sepsis: a narrative review. Transl Pediatr 2021. doi: $10.21037 /$ tp-21-1

9. Ganeshalingham A, Beca J. Serum biomarkers in severe paediatric traumatic brain injury—a narrative review. Transl Pediatr 2021. doi: $10.21037 / \mathrm{tp}-20-386$

10. Ong C, Lee JH, Leow MKS, et al. A narrative review of skeletal muscle atrophy in critically ill children: pathogenesis and chronic sequelae. Transl Pediatr 2021. doi: 10.21037/tp-20-298

11. Ravikumar N, Bansal A. Application of bench studies at the bedside to improve outcomes in the management of severe diabetic ketoacidosis in children—a narrative review. Transl Pediatr 2021. doi: 10.21037/tp-21-5

12. Mataya LA, Srinivasan V, Rand EB, et al. Multiple organ involvement and ICU considerations for the care of acute liver failure (ALF) and acute on chronic liver failure (ACLF) in children. Transl Pediatr 2021. doi: 10.21037/ tp-20-375

13. Balit CR, LaRosa JM, Ong JSM, et al. Sedation protocols in the pediatric intensive care unit: fact or fiction? Transl Pediatr 2021. doi: $10.21037 /$ tp- 20-328

14. Fan L, Lee JH. Enteral feeding and the microbiome in critically ill children: a narrative review. Transl Pediatr 2021. doi: $10.21037 /$ tp-20-349 
15. Berry KG, Seiple SM, Stellar JJ, et al. A scoping review to inform a multi-disciplinary approach for nutrition therapy in critically ill children with pressure injuries. Transl Pediatr 2021. doi: 10.21037/tp-21-3

16. Morrow BM. Building a culture of early mobilization in the pediatric intensive care unit—a nuts and bolts approach. Transl Pediatr 2021. doi: 10.21037/tp-20-324

17. Xiao T, Cheng Y, Lu G, et al. Pandemic considerations in pediatric critical care: what can we learn from COVID-19? Transl Pediatr 2020. doi: 10.21037/tp- 20-129

18. Fainberg N, Mataya L, Kirschen M, et al. Pediatric brain death certification: a narrative review. Transl Pediatr 2021. doi: $10.21037 / \mathrm{tp}-20-350$

19. Crowe L, Young J, Turner MJ. What is the prevalence and risk factors of burnout among pediatric intensive care staff (PICU)? A review. Transl Pediatr 2021. doi: 10.21037/ tp-20-400

20. Kirby L, Basu S, Close E, et al. Rationing in the Pediatric Intensive Care Uunit —ethical or unethical? Transl Pediatr 2021. doi: $10.21037 / \mathrm{tp}-20-334$

21. Long DA, Fink EL. Transitions from short to long-term outcomes in pediatric critical care: considerations for clinical practice. Transl Pediatr 2021. doi: 10.21037/tp-21-61

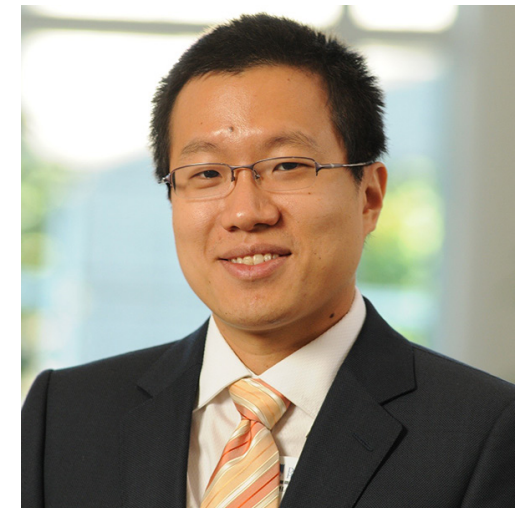

Jan Hau Lee

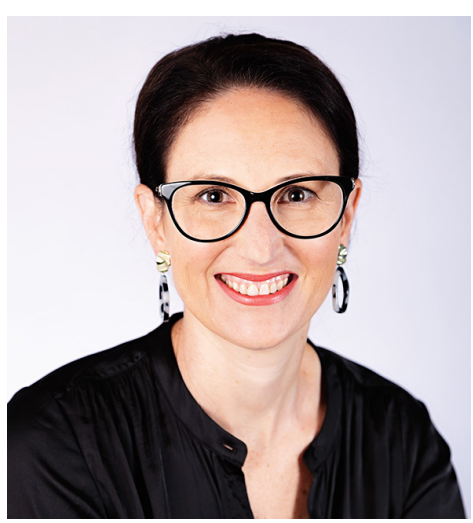

Debbie Long

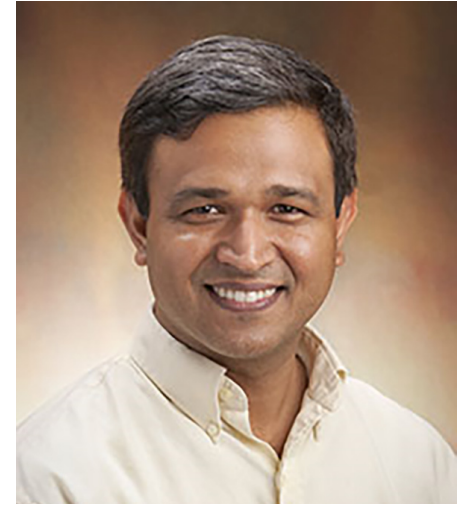

Vijay Srinivasan

Jan Hau Lee ${ }^{1,2}$

${ }^{1}$ Children's Intensive Care Unit, KK Women's and Children's Hospital, Singapore; ${ }^{2}$ Duke-NUS Medical School, Singapore, Singapore. (Email: lee.jan.hau@singhealth.com.sg)

Debbie Long ${ }^{3,4}$

${ }^{3}$ School of Nursing, Centre for Healthcare Transformation, Queensland University of Technology, Brisbane, Australia; ${ }^{4}$ Paediatric Intensive Care Unit, Queensland Children's Hospital, Brisbane, Australia.

(Email: da.long@qut.edu.au)

Vijay Srinivasan ${ }^{5,6}$

${ }^{5}$ Department of Anesthesiology, Critical Care and Pediatrics, University of Pennsylvania Perelman School of Medicine, Philadelphia, PA, USA; ${ }^{6}$ Department of Anesthesiology and Critical Care Medicine, The Children's Hospital of Philadelphia, Philadelphia, PA, USA.

(Email: SRINIVASAN@chop.edu)

Received: 06 September 2021. Accepted: 16 September 2021. doi: $10.21037 / \mathrm{tp}-21-429$

View this article at: https://dx.doi.org/10.21037/tp-21-429

Cite this article as: Lee JH, Long D, Srinivasan V. Translating scientific evidence into the art of caring for critically ill children across the globe. Transl Pediatr 2021;10(10):2643-2645. doi: $10.21037 / \mathrm{tp}-21-429$ 